\title{
EFFECT OF CIGARETTE SMOKING ON SERUM TRANSAMINASES
}

\section{O. D. ANYANWU and M. H. ETUKUDO}

(Received 8 May 2001; Revision accepted 20 August 2001)

\section{ABSTRACT}

Alanine transaminase and aspartate transaminase activity were assessed in 20 mild to moderate smokers, 20 heavy smokers and 20 non smokers, all males, aged between 17 and 35 years in Calabar Cross River State, Nigeria. The activity of both enzymes showed insignificant differences $(P>0.05)$ in mild to moderate smokers when compared to non-smokers. However, the activity of both enzymes were significantly elevated ( $P<0.005)$ in heavy smokers when compared to non-smokers. The results of this study point to the hazardous effects of cigarette smoking, which should be clearly highlighted in all campaigns against cigarette smoking.

Keywords: Cigarette smoking, alanine transaminases, aspartate transaminase.

\section{INTRODUCTION}

Cigarette smoking has been implicated in the pathogenesis of severat diseases among which include bronchial carcinoma, breast cancer and other forms of malignancies, chronic bronchitis, peptic ulcer and ischaemic heart disease (Boyu et al, 1984, Mann and Marmot, 1983). Also both epidemiological and clinical investigations have established that cigarette smoking increases the risk of cardiovascular and cerebrovascular diseases (Coull et al, 1986). Recent studies among Africans with pre-existing ischaemic heart disease have ranked cigarette smoking as a higher causative factor than .ypercholesterolaemia, hypertension, diabetes mellitus and obesity (Tricolat and Betrand, 1991). With the reported high prevalence of hypertension in Africa (Akinkugbe, 1972); increasing incidence of ischaemic heart disease on the continent (Tricolat and Betrand, 1991) and the growing level of preventable deaths caused by the yet unidentified and less publicized side effects of smoking, the potential dangers posed by the currently increasing cigarette consumption among Africans become obvious. This highlights the urgency for vigorou's campaign against cigarette smoking.
In addition to the enumerated known inevitable consequences of chronic cigarette smoking. It is obvious that more adverse effects resulting in various degrees of tissue pathology are also involved since about 4,7000 different chemicals and more than 50 human carcinogens have been identified in cigarette smoke (Hoffman and Hoffman, 1997). This calls ro several closer studies on the vario...... inse adverse effects of cigarette smoking. Studies have also shown that cigarette smoking causes hypoxia leading to ischaemia (Tricolat and Betrand, 1991) and a great deal of evidence indicate that cell membrane damage is a central factor in the pathogenesis of irreversible ischaemic cell damage, cell death and leakage of intracellular enzymes across the abnormally permeable cell membrane into plasma (Venticutachalam et al, 1983, Donald and Ralph, 2000l.

This study assesses possible alterations on serum transaminases following cigarette smoking and it is intended to provide information from the South Eastern part of Nigeria considering the fact that Boyu et al, 1984 has recorded that the prevalence of smoking in Africa in recent time is rising. 


\section{MATERIALS AND METHODS}

A total of 60 apparently healthy male subjects aged between 17 and 35 years were recruited randomly from students of University of Calabar, Cross River State, Nigeria. None of the súbjects studied had a history of hepatic, renal, cardiovascular, haematologic or endocrine disorder. No subject was on any medication and all subjects had no history of taking hard drugs.

Alcohol ere excluded from the study. These informatic,1 were obtained from the research questionnaire prepared for the selection of subjects.

The subjects were divided into two groups. Group A (non-smokers) and Group B (Smokers).The Smokers were further subdivided into two subgroups B1 (mild to moderate smokers) and B2 (heavy smokers), depending on their estimated daily consumption of cigarette. These information were also obtained from the research questionnaire for the selection of subjects. Mild to moderate smokers admitted to smoking 15 to

30 sticks of cigarette daily while heavy smokers admitted to smoking 31 to 40 sticks daily. All smokers admitted to regular consumption of the estimated number of sticks for at least 1 year. Occasional smokers were disqualified from the study.

Five milliliters of blood was collected from all the subjects by venepuncture, allowed to retract and then spun at $20,000 \mathrm{~g}$ for 5 minutes. The serum was obtained and analysed for alanine and aspartate transaminase activity by the use of the Randox kit based on the modified method of Reitman and Frankel (1957).

Table 1: Values of alanine transaminase (ALT) activity and aspartate transaminase (AST) activity in non smokers, mild to moderate $(\mathrm{M} / \mathrm{M})$ smokers and heavy smokers.

\begin{tabular}{|c|c|c|c|}
\hline Emzymes & $\begin{array}{c}\text { Group A } \\
\text { (Non-Smokers) } \\
(\mathrm{n}=20)\end{array}$ & $\begin{array}{c}\text { Group BI } \\
(\mathrm{M} / \mathrm{M} \text { Smokers }) \\
(\mathrm{n}=20)\end{array}$ & $\begin{array}{c}\text { Group B2 } \\
\text { (Heavy Smokers) } \\
(n=20)\end{array}$ \\
\hline $\begin{array}{l}\text { ALT (U/L) Mean } \pm \mathrm{SD} \\
\text { Range } \\
\text { Percentage Increase } \\
\text { t-test }\end{array}$ & $\begin{array}{l}5.30 \pm 2.34 \\
(2-12)\end{array}$ & $\begin{array}{l}6.25 \pm 97 \\
(2-12) \\
15.2 \\
(P>0.05)\end{array}$ & $\begin{array}{l}10.1 \pm 3.54 \\
(4-17) \\
47.5 \\
(P<0.05)\end{array}$ \\
\hline $\begin{array}{l}\text { AST (U/L) Mean } \pm \text { SD } \\
\text { Range } \\
\text { Percentage Increase } \\
\text { t-test }\end{array}$ & $\begin{array}{l}6.55 \pm 3.41 \\
(4-16)\end{array}$ & $\begin{array}{l}7.30 \pm 3.63 \\
(4-16) \\
10.3 \\
(P>0.05)\end{array}$ & $\begin{array}{l}14.5 \pm 3.30 \\
(10-19) \\
54.8 \\
(P<0.05)\end{array}$ \\
\hline
\end{tabular}

$$
N=\text { no. of cases }
$$

\section{RESULTS}

Table 1 shows the values of the activity of aspartate and alanine transaminase activity in non-smokers, mild to moderate and heavy smokers. There were no significant differences $(P>0.05)$ in the values of alanine transaminase activity and aspartate transaminase activity amongst our mild to moderate smokers (group B1). However, the percentage increase of alanine transaminase activity (15.2\%) was about one and a half times greater than that of aspartate transaminase activity $(10.3 \%)$ in this subject group. 
The mean alanine transaminase activity was found to be $6.25 \pm 2.97 \mathrm{U} / \mathrm{L}$ in mild to moderate smokers and $10.1 \pm 3.54 \mathrm{U} / \mathrm{L}$ in heavy smokers while that for aspartate transaminase activity was $7.30 \pm 3.63 \mathrm{U} / \mathrm{L}$ in mild of moderate smokers and $14.5 \pm 3.30 \mathrm{U} / \mathrm{L}$ in heavy smokers. The activity of both enzymes in heavy smokers where significantly higher $(P>0.05)$ than those of the controls. Also in heavy smokers, the activity of aspartate transaminase showed more significant increase with a percentage increase

of $54.8 \%$ than alanine transaminase activity with a percentage increase of $47.5 \%$.

The activities of both enzymes appeared to increase with the number of cigarette consumed daily from non-smokers, mild to moderate to heavy smokers.

\section{DISCUSSION}

The values of alanine transaminase and aspartate transaminase activity were higher in smokers compared to non-smokers. The higher mean activity of alanine transaminase and aspartate transaminase in mild to moderate and heavy smokers is consistent with the findings earlier reported by Tricolat and Betrand (1991), Mann and Marmot (1983) that cigarette smoking introduces various degrees of pathology in various tissues of smokers. The higher values of the activity of these enzymes in smokers compared to non smokers is a result of increased leakage of these enzymes from the major tissues were they are present in abundance as a result of the toxic effect of cigarette smoke fractions on these tissues (Kristensen and Horder, 1996, Kristensen, 1994).

The site of major toxic effect in mild to moderate smoking is possibly the liver. This is because the percentage activity difference of alanine transaminase from mild to moderate smokers was observed to be higher than that of aspartate transaminase. The higher differential increase in alanine transaminase activity in mild to moderate smokers is possible due in part to the fact that the alanine transaminase is almost entirely liver specific and also alanine transaminase is solely cytoplasmic while aspartate transaminase is both cytoplasmic and mitochondrial (Baron et al., 1989). Therefore apparently, incidence of gradual hepatic tissue degeneration will lead to the leakage of more alanine transaminase into plasma than aspartate transaminase. Thus the serum activity of alanine transaminase increases more than that of aspartate transaminase. This is so because increased leakage of these enzymes in most pathological conditions (not involving cell death) is associated with loss of plasma membrane integrity of the cells with the mitochondria still intact (Donald and Ralph, 2000). In addition, the longer periods between the smoking of each stick of cigarette in mild to moderate smokers also ensures a relative adequate tissue oxygenation such that tissue hypoxia, ischaemia, and infarction are rare consequences of mild to moderate smoking (Aronow, 1979, Korubo et al., 1997). Apparently therefore aspartate transaminase release from extrahepatic tissues was still within the baseline levels.

The reverse was the case in heavy smokers were the major site of toxic effect has possibly shifted to the extrahepatic tissues that also have high levels of these enzymes and sharply respond to hypoxia and ischaemia. Such tissues are the myocardium and skeletal muscles. In this subject group, there is significantly high level of activity in both enzymes when compared to non-smokers with the percentage activity in both enzymes compared to non-smokers. with the percentage activity difference of aspartate transaminase being higher than that of alanine transaminase. This is because alanine transaminase is greatly compartmentalized in the hepatic tissue than other tissues in the body while aspartate transaminase is also found in abundance in cardiac muscle, skeletal muscle and ervthrocytes in addition to that found in hepatic tissue (Donald and Ralph, 2000). Therefore bouts of tissue hypoxia as a result of heavy smoking, reduced oxygen delivery to tissues and high 

Tricolat, P. and Betrand, D. E., 1991. Aspects epidemoguques de la maladiecoronaire chezlenoir African. Apropos de $103 \mathrm{Ca}$. Resultanted sd 1 anaquete multicentraque. prospective contronatic. Tropical cardiology 17: $7-20$.
Venkatachalam, M. A., Daniel, R. P. and Silivia, M. M., 1983. Salvage of Ischaemic Cells by impermeant solute and ATP, Lab Invest. $4 \varsigma_{1} \cdot 1 \cdot 1$. 